\title{
BEPERS pilot study: an experiment with X-band synthetic aperture radar over Baltic Sea ice
}

\author{
MATTI LEPPÄRANTA, \\ Finnish Institute of Marine Research, SF-00931 Helsinki, Finland \\ Risto Kuittinen, * \\ Finnish Geodetic Institute, SF-00240 Helsinki, Finland \\ JAN ASKNe \\ Department of Radio and Space Science, Chalmers University of Technology, \\ S-41296 Goethenburg, Sweden
}

\begin{abstract}
Remote-sensing methods are the primary ones used for ice mapping in the Baltic Sea. A major methodological improvement is now being introduced by satellite radars due to their weather independency and high resolution. To learn how to use ERS-1 synthetic aperture radar (SAR) data, an extensive field programme BEPERS (Bothnian Experiment in Preparation for ERS-1) with airborne SARs has been arranged. The BEPERS pilot study was undertaken in 1987 using the French VARAN-S X-band SAR. The SAR was flown on 1 day over four study areas of size approximately $10 \mathrm{~km} \times 50 \mathrm{~km}$, and intensive validation observations were made. The data were most useful for the education they provided on how to work with SAR in sea-ice mapping. They have been used for developing SAR image-analysis methods, back-scatter modelling investigations and geophysical validation of SAR imagery. Cleaning-up of images consisted of speckle reduction and segmentation. Back-scatter characteristics of undeformed ice and ridges were examined. Ice-type classification was based on the box-classification method. Eight ice types were defined but basically only two types, undeformed ice/open water and deformed ice, could be discriminated. Two basic problems of high practical importance remained: how to discriminate between (1) open water and undeformed ice, and (2) ridged ice and brash ice. The data further showed illustrative examples of SAR imagery over sea ice.
\end{abstract}

\section{INTRODUCTION}

The Baltic Sea is a shallow, semi-enclosed brackish water basin. It is part of the seasonal sea-ice zone. Ice occurs annually for up to 6 months and to the extent of $12-100 \%$ ice coverage. All the main harbours are, however, kept operational throughout the year with the help of 20-30 powerful icebreakers. It is very important to the economics of navigation to map and predict the ice conditions properly, and hence much effort is put into sea-ice research in support of the winter traffic (e.g. Leppäranta, 1986).

The present routine sources of ice information are conventional in situ observations from ships and shore, aerial reconnaissance, and optical and thermal satellite imagery (NOAA/AVHRR). Most data are highly weather-dependent. Radars solve this weather problem and

\footnotetext{
* Formerly at Instrument Laboratory, Technical Research Centre of Finland, SF-02100 Espoo, Finland.
}

provide high-resolution data, and therefore the next major improvement in operational sea-ice mapping is expected to come with satellite synthetic aperature radars (SAR). The European Space Agency's (ESA) remote-sensing satellite ERS-1, to be launched in 1991, carries a SAR for research purposes. This is the first western satellite SAR since SEASAT which survived only a very short time in 1978. The ERS-1 programme contains a substantial sea-ice project PIPOR (A Programme for International Polar Oceans Research; Battrick and Rolfe, 1985) in which a regional sub-programme for the Baltic Sea is included.

ERS-1 preparations commenced in Finland and Sweden in 1985, focusing on the SAR. A field programme BEPERS (Bothnian Experiment in Preparation for ERS1) with airborne SARs was organized. The first effort was the BEPERS pilot study performed in the winter of 1987 (Leppäranta and others, 1989), followed by the main experiment BEPERS-88 a year later (Leppäranta and Thompson, 1989). The objective was to "produce sea-ice remote-sensing data similar to ERS-1 data together with high-quality ground truth and supporting remote-sensing 


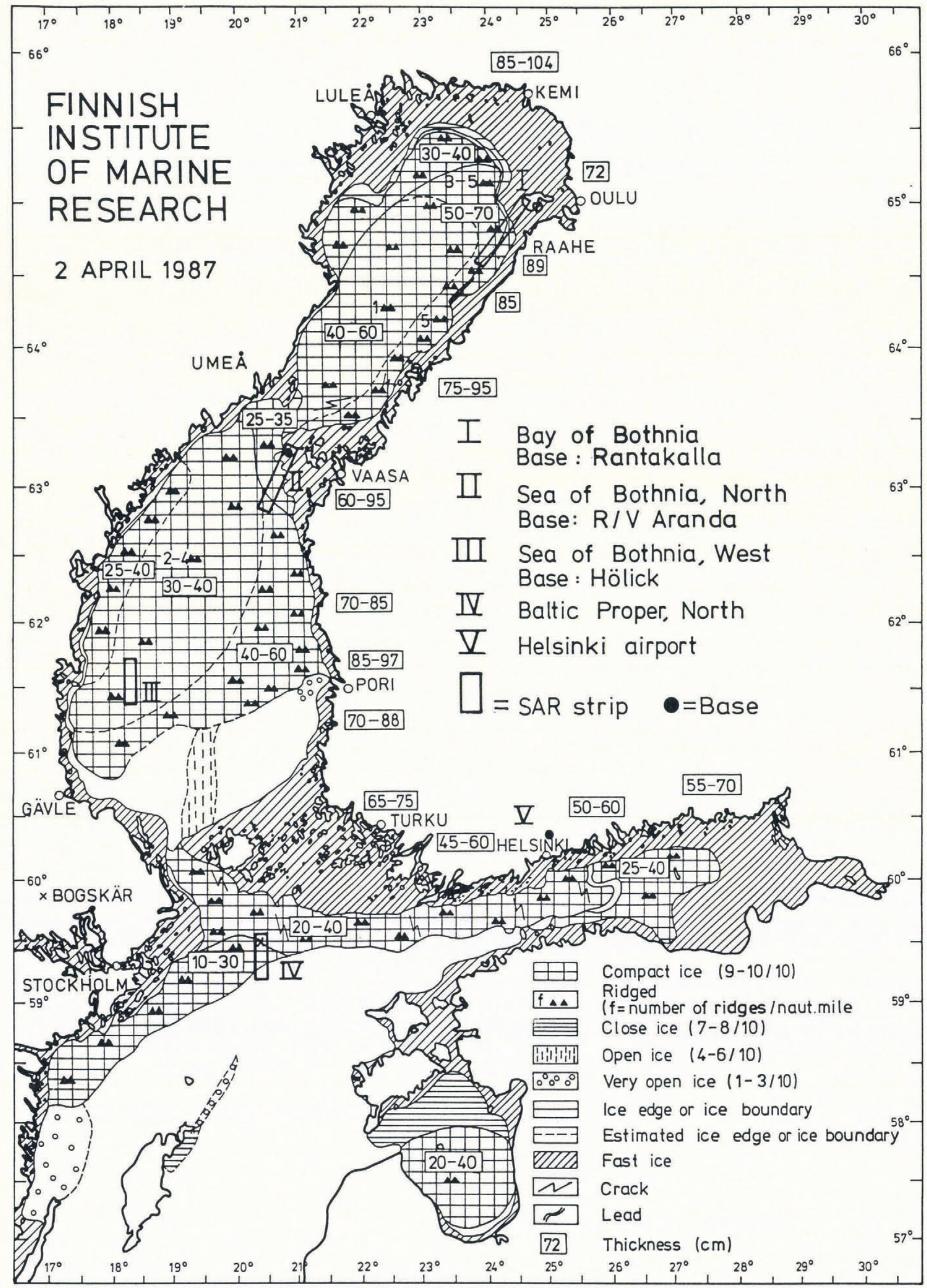

Fig. 1. Baltic Sea ice chart, 2 April 1987 (Finnish Institute of Marine Research, 1987). Also shown are the locations of the bases and study areas in BEPERS pilot study. 


\begin{tabular}{|c|c|c|c|c|c|c|}
\hline \multirow[t]{2}{*}{ Data type } & \multirow[t]{2}{*}{ Frequency } & \multicolumn{4}{|c|}{ Study area } & \multirow[t]{2}{*}{ Time } \\
\hline & & I & II & III & IV & \\
\hline SAR & X-band & $x$ & $x$ & $x$ & $x$ & 2 April \\
\hline Ground truth & & $x$ & $x$ & $x$ & & 30 March-3 April \\
\hline Routine ice data & & $x$ & $x$ & $x$ & $x$ & 30 March-3 April \\
\hline Aerial photography & Visible & $x$ & $x$ & & $x$ & 2 April \\
\hline SLAR & X-band & & $x$ & $x$ & & 2 April \\
\hline IR scanner & $8-14 \mu \mathrm{m}$ & & $x$ & $x$ & & 2 April \\
\hline Impulse radar & $500 \mathrm{MHz}$ & & $x$ & & & 30 March-1April \\
\hline NOAA & Visible, IR & $x$ & $x$ & $x$ & $x$ & 31 March, 2 April \\
\hline SPOT & Visible & & $x$ & $x$ & & $31 \mathrm{March}$ \\
\hline
\end{tabular}

The French VARAN-S airborne radar was chartered from GDTA for the experiment (Vaillant, 1985; Vaillant and Wadsworth, 1987; Kuittinen, 1988). The aircraft used was Boeing B-17-G FBEEA, "Chateau de Verneuil". In this experiment the SAR mode was used with: frequency $9.375 \mathrm{GHz}$ (X-band); horizontal polarization (HH); flight altitude about $6000 \mathrm{~m}$ and swath width $10 \mathrm{~km}$; incidence angle from $11^{\circ}$ to $67^{\circ}$ (right-look direction); spatial resolution in single look $3 \mathrm{~m} \times 3 \mathrm{~m}$, nine looks $9 \mathrm{~m} \times 9 \mathrm{~m}$; and quick look $70 \mathrm{~mm}$ black-and-white film.

The data set consists of 20 scenes of $9 \mathrm{~m} \times 9 \mathrm{~m}$ resolution data and four scenes of $3 \mathrm{~m} \times 3 \mathrm{~m}$ data (Table 2), each scene $10 \mathrm{~km} \times 10 \mathrm{~km}$.

observations". The BEPERS data are used for: (1) development of algorithms for processing and enhancing SAR sea-ice images; (2) basic research into microwave back-scatter from brackish water ice; (3) development of algorithms for determination of geophysical sea-ice properties from SAR images; and (4) evaluating the potential of SAR in operational sea-ice mapping and for use in numerical models.

This paper gives a final summarizing report of the BEPERS pilot-study experiment, results and success. The experiment was organized by the Technical Research Centre of Finland and the Finnish Institute of Marine Research, with 11 other institutes from Finland and Sweden participating in the field programme. The SAR data were provided by the French X-band VARAN-S, chartered from Groupement pour le Développement de la Télédetection Aérospatiale (GDTA), Toulouse, France. Four study areas were imaged with the SAR representing different ice conditions, and intensive ground, airborne and space-borne validation observations were made to ensure correct interpretation of the SAR imagery. The field programme and the data obtained have been described in detail in Winter Navigation Research Board (1988). As this was the first SAR field campaign in the region, most of the results are qualitative. Quantitative investigations were performed on the back-scatter characteristics of various ice types. The qualitative analysis is by no means of minor importance; it provides the basis for understanding the possibilities and problems of sea-ice mapping with SAR in the Baltic Sea.

\section{THE BEPERS PILOT-STUDY EXPERIMENT}

The period of the experiment was 30 March-3 April 1987. The operation day of the SAR flight was 2 April and the

Table 2. BEPERS pilot-study SAR data from 2 April 1987

\begin{tabular}{|c|c|c|c|c|c|c|}
\hline \multirow[t]{2}{*}{ Area } & \multirow[t]{2}{*}{ Time (UTC) } & \multirow{2}{*}{$\begin{array}{l}\text { Size } \\
\mathrm{km}^{2}\end{array}$} & \multicolumn{2}{|c|}{ Digital } & \multicolumn{2}{|c|}{ Analogue } \\
\hline & & & Resolution & No. of scenes & Photographs & Quick look \\
\hline I & 1000 & $60 \times 10$ & $9 \times 9 \mathrm{~m}$ & 6 & 6 & 1 \\
\hline II & 1100 & $70 \times 10$ & $\begin{array}{l}9 \times 9 \mathrm{~m} \\
3 \times 3 \mathrm{~m}\end{array}$ & $\begin{array}{l}7 \\
2\end{array}$ & 7 & 1 \\
\hline III & 1230 & $40 \times 10$ & $\begin{array}{l}9 \times 9 \mathrm{~m} \\
3 \times 3 \mathrm{~m}\end{array}$ & $\begin{array}{l}4 \\
2\end{array}$ & 4 & 1 \\
\hline IV & 1400 & $30 \times 10$ & $9 \times 9 \mathrm{~m}$ & 3 & 3 & 1 \\
\hline
\end{tabular}


whole period was used for the validation observations. Four study areas were chosen in the northern part of the Baltic Sea (Fig. 1). In each area, SAR imaging was performed along a strip which was $40-70 \mathrm{~km}$ long and $10 \mathrm{~km}$ wide. The bases and study areas are briefly described as follows. Area I (Bay of Bothnia). The base was a coastal hotel. The helicopter of the Finnish icebreakers in the Bay of Bothnia was used in the field work. One-third of the study area consists of fast ice. Area II (northern Sea of Bothnia). The base was R/V Aranda, moored to fast ice at the fast-ice boundary. Aranda was the main ground-data base with one helicopter aboard. Again the strip begins from the fast-ice region. Area III (western Sea of Bothnia). The base was outside a Swedish pilot station Hölick in Hornslandet from which helicopter transport was arranged to an ice base $40 \mathrm{~km}$ offshore. The area was located in the drifting ice field. Area $I V$ (northern Baltic proper). No ground base; the area was imaged because the main ice edge was here. Area $V$ (Helsinki airport). This was the base of the SAR and aerial photography aeroplanes.

A total of 23 scientists took part in the field programme. The weather was very good for working conditions. Southerly to easterly flow of mild air prevailed. The wind was weak and the air temperature rose to above zero in the afternoons. The programme was successfully carried through with no major drawbacks. Table 1 gives a summary list of the data obtained, but a more detailed description follows below.

Twelve trihedral aluminium corner reflectors were installed on the ice in areas I-III (four on each). The side length of the square base was $1 \mathrm{~m}$, implying a radar crosssection of $7300 \mathrm{~m}^{2}$ or scattering coefficient of $39 \mathrm{~dB} \mathrm{~m}^{-2}$. The reflectors were identified in the one-look images showing signs of saturation in several (4-8) pixels in the range direction and a few (1-2) pixels in the azimuth as well as side-lobe effects. Due to the saturated response, the radar reflectors could be used for marking purposes but not for absolute calibration.

Proper marking of the study areas and locating the observation sites is needed in order to compare various remote-sensing products with each other and with ground measurements, and to correct geometric errors in the remote-sensing data. Fixed landmarks, such as small islands, were most useful for this purpose. Far in the sea in the pack-ice field, the geographical coordinates were obtained using the Decca Navigator system of the helicopters with an accuracy of about $100 \mathrm{~m}$. This accuracy is too low for pixel-wise validation of the SAR imagery but sufficient for examination of the back-scatter from various ice types in patches larger than $100 \mathrm{~m}$ in size.

The aerial photography provided the main airbornevalidation data. In the study areas I, II and IV, $2-7 \mathrm{~km}$ wide strips were photographed inside the SAR strips. The markers consisted of a cross or circle made either by using dye or by shovelling snow away from the top of the ice. The Swedish Coast Guard Cessna aeroplane with IRscanner and SLAR (side-looking airborne radar) was used in study areas II (southern part) and III. The SLAR works in the X-band, uses vertical polarization and has a spatial resolution of approximately $75 \mathrm{~m}$. The swath width is $20 \mathrm{~km}$ on both sides of the aircraft and the angle of incidence is between $45^{\circ}$ and $87^{\circ}$. An impulse radar from
Table 3. Ground-measurement programme in BEPERS pilot study

Object Study area

I

II

III

IV

General description

Ice and snow thickness

Ice structure

Ice salinity and

temperature

Dielectric constant

Snow density and

grain-size

Free-water content

of snow

Snow and surface

temperature

Surface topography

Meteorological

observations

$\begin{array}{llll}\times & \times & \times & \times \\ \times & \times & \times & \times \\ & \times & & \end{array}$

$x \quad x$

$\times$

$\times$

$\times$

$x \quad x$

$\times \quad x$

$\times \quad x$

$\times$

Lund University of Technology was used in area II, aiming to map the thicknesses of ice and snow, and the surface topography.

The satellite data consist of several NOAA images and one SPOT image. Most of the data are from 31 March because of the weather conditions. However, the ice situation did not change much during 31 March-2 April except for a small amount of drifting in areas II-IV.

The ground-data programme consisted of a general description of the ice conditions in the study areas and detailed measurements in selected patches (Table 3). The general description was mainly based on helicopter reconnaissance flights. Routine observations of the Finnish and Swedish ice services were used for additional information. The products are presented in ice-chart form, similar to routine ice charts but on a finer scale, describing ice type and thickness. The detailed data describe the properties of the ice-snow system relevant for radar remote sensing. Most data were taken from the vicinity of the Aranda base. Using helicopters, around 20 sites were sampled in the pack-ice field in areas I-III.

\section{ICE AND SNOW PROPERTIES}

\subsection{General}

The winter of 1987 was severe in the Baltic Sea. The ice coverage was at maximum $96 \%$ and the level ice thickness exceeded $1 \mathrm{~m}$ in the north; the climatic averages are $50 \%$ and $72 \mathrm{~cm}$. A general map of the ice situation on the SAR flight day is shown in Figure 1. Table 4 shows the ranges of ice and snow properties in the study areas I-IV (Håkansson and Thompson, 1988; Leppäranta, 1988; Leppäranta and others, 1988; Vainio, 1988). The ice 
compactness was $90-100 \%$ and the ice thickness ranged from $10 \mathrm{~cm}$ to nearly $1 \mathrm{~m}$. The ridge density was $1-7 \mathrm{~km}^{-1}$, which is quite normal. The height of the ridges was generally $50-100 \mathrm{~cm}$ and the maximum was $350 \mathrm{~cm}$.

Figure 2 is a SPOT image over study area II. The fast-ice region shows up clearly with the white snow surface. In the pack-ice field, ice ridges show up well as white lines; the level spots are at first bare (dark) and then become snow-covered (white) with distance from the coast. Between the time of this SPOT image and the SAR flights, a narrow lead opened at the fast-ice boundary.
The Baltic Sea is brackish water ice. It resembles sea ice in that the ice-crystal structure is similar to that of seaice crystal structure and the brine is the major impurity within the ice. The results of ice-coring in area II have been given in Leppäranta and others (1988). The samples show that on average $25 \%$ of the ice was granular, grainsize less than $5 \mathrm{~mm}$, and the rest columnar. The granular ice was mainly snow-ice on the top. Also, alternating columnar and granular layers occurred in the ice pack and at these sites the granular layers could be frazil ice. The total ice salinity was $0.4-1.2 \%$. In areas II-III, it was only

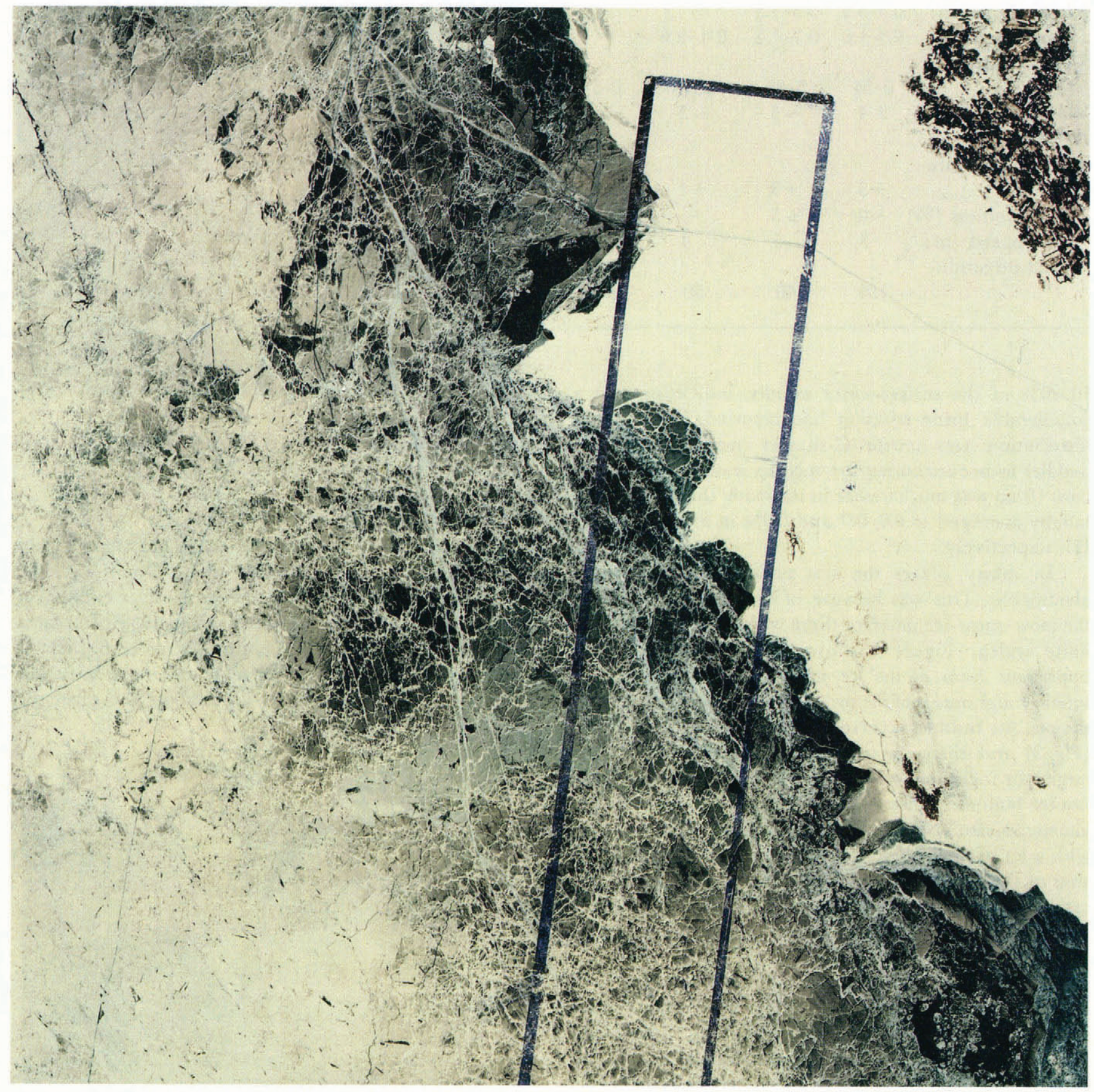

Fig. 2. Multispectral SPOT image over the northern Sea of Bothnia on 31 March 1987. Imaged area is $60 \mathrm{~km} \times 60 \mathrm{~km}$, pixel size is $20 \mathrm{~m} \times 20 \mathrm{~m}$. Source: Satellitbild $i$ Kiruna AB, Sweden. Also shown is the location of the SAR strip. 
Table 4. Ice and environmental conditions in BEPERS pilotstudy areas on 2 April (-, no data)

Study area

I II III IV

\begin{tabular}{|c|c|c|c|c|}
\hline $\begin{array}{l}\text { Ice compactness } \\
(\%)\end{array}$ & $\sim 100$ & $90-100$ & $90-100$ & $90-100$ \\
\hline Ice thickness $(\mathrm{cm})$ & $55-80$ & $20-75$ & $40-50$ & $10-40$ \\
\hline \multicolumn{5}{|l|}{ Ridge density } \\
\hline$\left(\mathrm{km}^{-1}\right)$ & $1-7$ & $2-4$ & $4-6$ & - \\
\hline Ridge height $(\mathrm{m})$ & $0.3-3.5$ & $0.3-1.5$ & - & - \\
\hline Ice salinity $(\%)$ & $0.5-1.0$ & $0.7-1.2$ & $0.4-0.6$ & - \\
\hline \multicolumn{2}{|l|}{ Snow thickness } & $0-30$ & $0-15$ & $0-5$ \\
\hline Water salinity (\%o) & $2-4$ & $\sim 5$ & $\sim 5$ & 6 \\
\hline \multicolumn{5}{|l|}{ At SAR time: } \\
\hline $\begin{array}{l}\text { Air temperature } \\
\left({ }^{\circ} \mathrm{C}\right)\end{array}$ & +3 & +3 & +1 & +1 \\
\hline Snow wetness (\%) & $\sim 0$ & $3-5$ & - & - \\
\hline Wind speed $\left(\mathrm{m} \mathrm{s}^{-1}\right)$ & 3 & 5 & 4 & 7 \\
\hline \multicolumn{5}{|l|}{ Wind direction } \\
\hline$\left({ }^{\circ}\right)$ & 150 & 40 & 50 & 90 \\
\hline
\end{tabular}

$10-20 \%$ of the surface-water salinity, indicating that a considerable brine rejection had occurred. The vertical distribution was mirror C-shaped (maximum in the middle) as occurs during the melting season. The uppermost $10 \mathrm{~cm}$ was much fresher in the south: this upper-layer salinity averaged to $0.6,0.7$ and $0.3 \%$ in areas I, II and III, respectively.

In many places the ice surface was not easily identifiable. This was because of the snow-ice layer; at the snow-snow-ice interface there was a transition layer of finite width. Figure 3 shows a cross-section of the uppermost $5 \mathrm{~cm}$ of the ice at Aranda. The root-meansquare roughness is of the order of $2 \mathrm{~mm}$ in this $3 \mathrm{~cm}$ long sample. Air bubbles occurred in the ice in the upper layer (Fig. 3) and their diameter was typically $1-8 \mathrm{~mm}$. The largest air inclusion was about $30 \mathrm{~mm}$ in diameter. At the fast-ice boundary in area II, one particular spot of some kilometres size was found. The surface was dry and bare with a lot of air inclusions seen from above (Fig. 4). The sizes of the air inclusions were from millimetres to a few centimetres; large ones were not rare. This spot gave a much higher back-scatter than the snow-covered fast-ice region.

The dielectric constant of the Baltic ice had been examined by Hallikainen and others (1988) through direct measurements (at $10 \mathrm{GHz}$ ). The resulting penetration depth was $10 \mathrm{~cm}$ at a brine volume of $2.5 \%$ and $3 \mathrm{~cm}$ at a brine volume of $5.0 \%$. This range corresponds to the prevailing conditions; the characteristic penetration depth for the present ice is therefore $5 \mathrm{~cm}$.

The snow cover on top of the ice has a key role in seaice remote sensing through its high temporal and spatial variability. In the BEPERS pilot-study case, the thickness

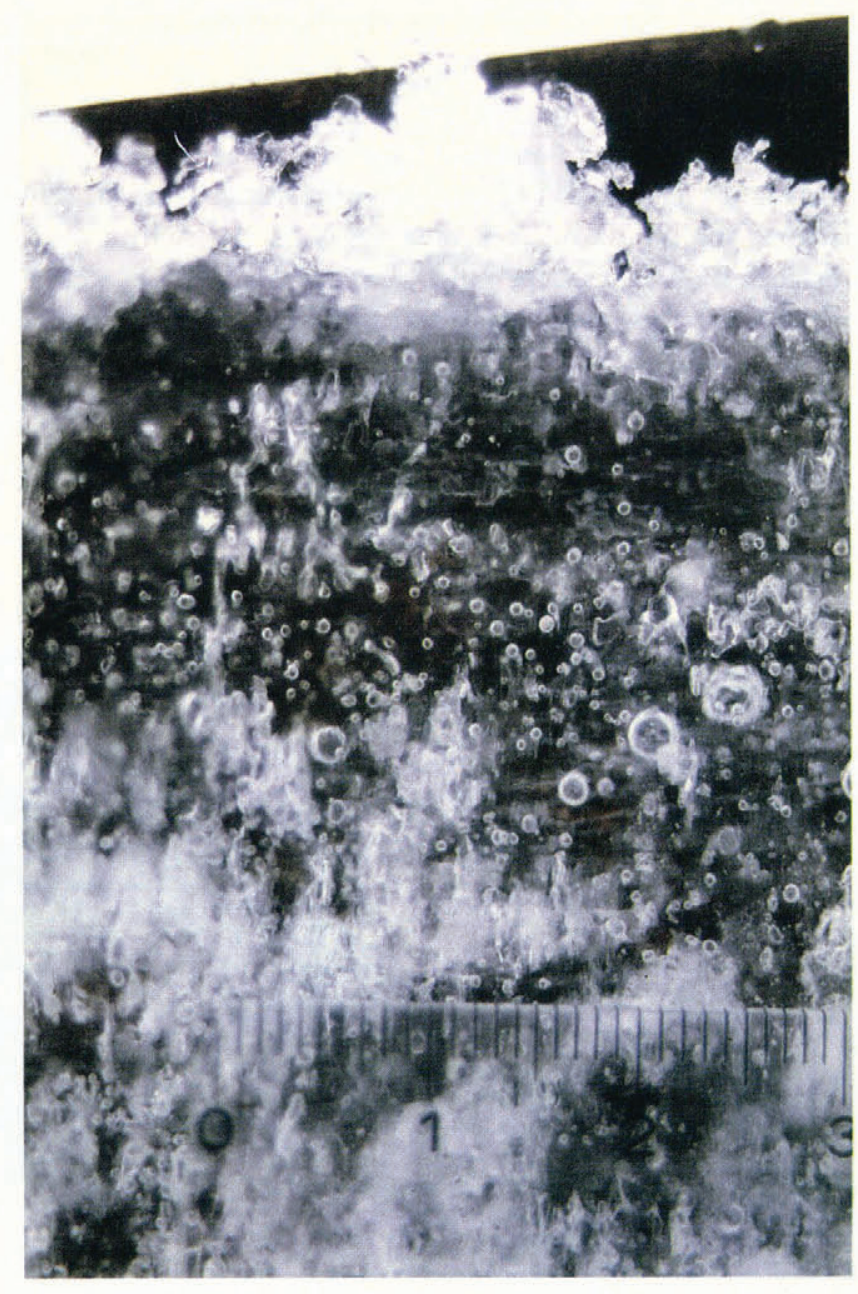

Fig. 3. Vertical cross-section of the surface layer of ice at Aranda base. Tick-mark spacing is $1 \mathrm{~mm}$.

of snow was $0-30 \mathrm{~cm}$, density $0.25-0.35 \mathrm{Mg} \mathrm{m}^{-3}$ and wetness $0-10 \%$. The grain-size was $1-3 \mathrm{~mm}$ and the grains were weakly frozen together into larger clumps, of the order of $1 \mathrm{~cm}$ (Leppäranta and others, 1988). In places there was a slush layer at the bottom, up to $4 \mathrm{~cm}$ thick. It was a mixture of sea water and snow and the salinity was about $1 \%$. Even in the snow layers above the slush the salinity was $0.1 \%$.

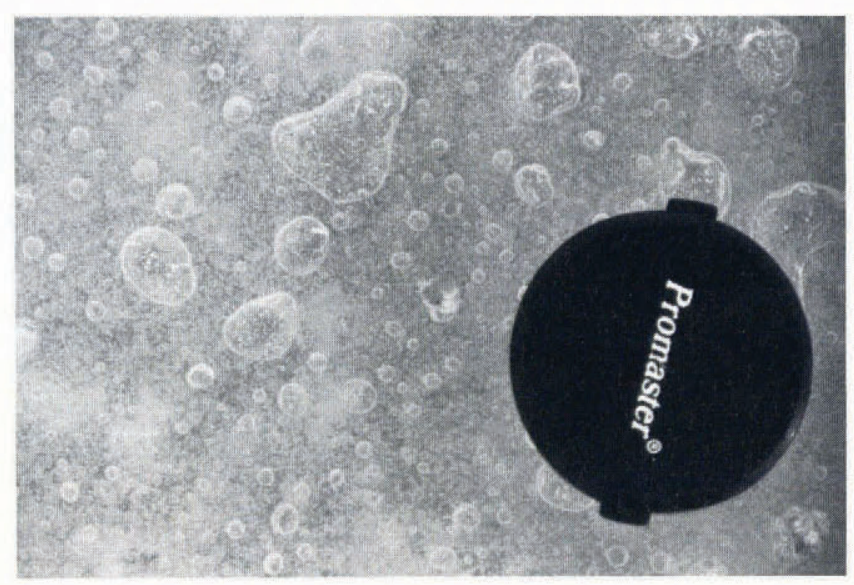

Fig. 4. Photograph of a bare fast-ice spot. Diameter of the scale circle is $60 \mathrm{~mm}$. 


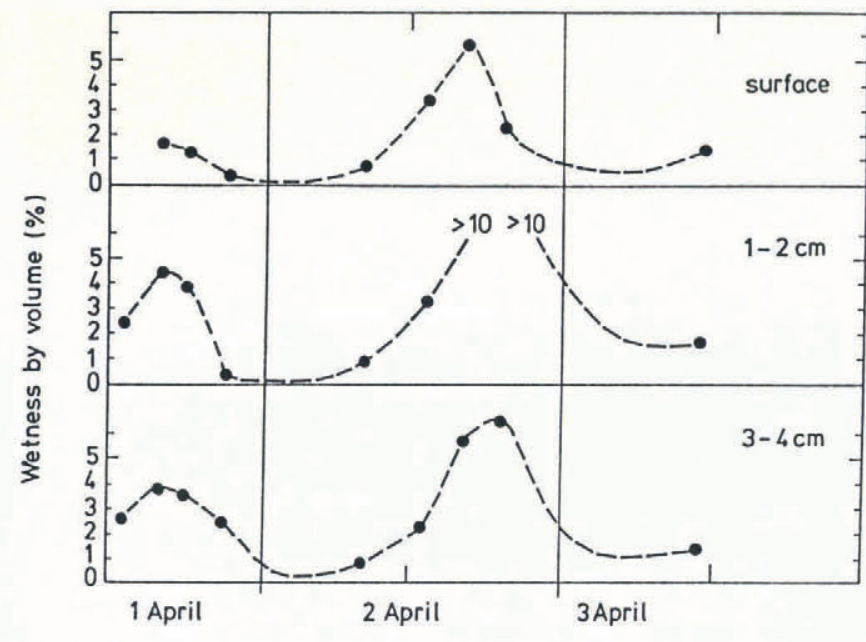

Fig. 5. Diurnal variation of the snow wetness in the top $4 \mathrm{~cm}$ layer at the Aranda base (Hallikainen and others, 1988).

The radar penetration depth into the snow is highly sensitive to the snow wetness. During the BEPERS pilot study, substantial variations occurred as the air temperature cycled between negative at nights and positive in the day-time (Hallikainen and others, 1988). Figure 5 shows the snow-wetness observations for the top $4 \mathrm{~cm}$ of the snow layer; similar behaviour also occurred deeper. For the Xband frequency, the penetration depth becomes less than $10 \mathrm{~cm}$ as the wetness reaches $3 \%$ (Hallikainen, 1984).

In the ground programme in area II, the high spatial variability in conditions relevant for SAR was noted (Leppäranta and others, 1988). In the snow cover there were thick wet slush spots and dry spots occurring in apparently random manner. This seemed to go down to the wavelengths of order of the SAR pixel size.

\subsection{SAR imaging time}

At the time of the SAR flight the snow was wet in area II and south, which meant that the major part of the backscattered signal came from the snow layer; the penetration depth of the SAR was less than $10 \mathrm{~cm}$. In the bare spots the penetration depth into the ice was of the order of $5 \mathrm{~cm}$. In area $I$, the air temperature was above zero at the time of the SAR flight but field observations indicated that just $1 \mathrm{~h}$ before the flight the snow was still dry (Vainio, 1988).

The aerial photography was taken within $2-3 \mathrm{~h}$ of the SAR coverage. During this time gap there were only minor changes in the ice conditions: in area I the ice was stationary, whereas in the other areas the ice was moving very slowly and the snow was in the melting stage. Due to the melting stage, the thermal imaging did not provide essential information.

\section{SAR IMAGE PROCESSING}

Pre-processing of the raw SAR data was done by GDTA in France. The software structure has been presented by Vaillant (1985) and Vaillant and Wadsworth (1987). The images were processed up to the full resolution $(3 \mathrm{~m})$ and to the lowest resolution $(9 \mathrm{~m})$ using 16 bits per pixel. The low-resolution data were corrected for the distance dependency by multiplying the image by the inverse of its mean radiometry, which seems to be a good approximation because the images are quite homogeneous. However, this does not provide an opportunity of analysing the original recorded back-scattering, which may cause problems in interpreting the data and results. In the scenes processed up to the full resolution, this kind of calibration has also been made but the mean radiometry data were delivered with the image data. This enables the computation of the original pixel values. Interference between the antenna and the aircraft caused interferometric patterns in images especially noticeably in those areas where the back-scattering was low.

The inherent problem with SAR images is the speckle. Speckle reduction has generally been made through simple averaging or by using specified adaptive or edgepreserving filters. Averaging the image in windows of different sizes was studied by Kemppainen (1989). The growth of the window size smooths the image effectively but a drawback of averaging is that the spatial resolution is then also reduced and linear features that are only a couple of pixels wide are lost. Averaging in a $3 \times 3$ neighbourhood of a pixel was found most suitable. Adaptive filtering avoids deterioration of resolution and preserves edges in the image by computing filter coefficients from local statistics. An adaptive filter, according to Lee (-1986), was used by Askne and Johansson (1988).

Kemppainen (1989) also examined image segmentation methods. The most suitable method was found to be the so-called box classification (or parellelepiped classification). In this system the intensity limits for a given number of classes are first determined. Segment areas are filled with the segment mean from the original image. Segmentation methods like this are usually not well suited for highly speckled images and speckle reduction is needed before segmentation.

\section{BACK-SCATTER MODELLING}

Analysis and mathematical modelling of SAR backscattering provides a method for examing the possibilities of SAR in sea-ice mapping. The models tell us to what extent variations in snow and ice properties can be expected to be distinguished in SAR images. For practical reasons, the most important ice features in ice mapping are ice ridges in the Baltic Sea. Therefore, the main interest in modelling has been in understanding the back-scattering of deformed ice, in particular ice ridges, and the possibilities of determining ridge properties from SAR images (Johansson and Askne, 1987; Manninen, 1990).

The BEPERS pilot-study data set was the first for the Baltic Sea ice to be used for modelling research. Because of the small wavelength of VARAN-S SAR $(3.2 \mathrm{~cm})$, backscattering is related mainly to the surface and upper-layer structure of the ice or snow. Consequently, for modelling the back-scatter from ridges, the key factors are the smallscale surface roughness, dielectric constant and the geometry of the ice-block arrangement (Manninen, 1990).

The back-scattering coefficient of three ice types was examined by Johansson (1988) from the BEPERS pilot- 


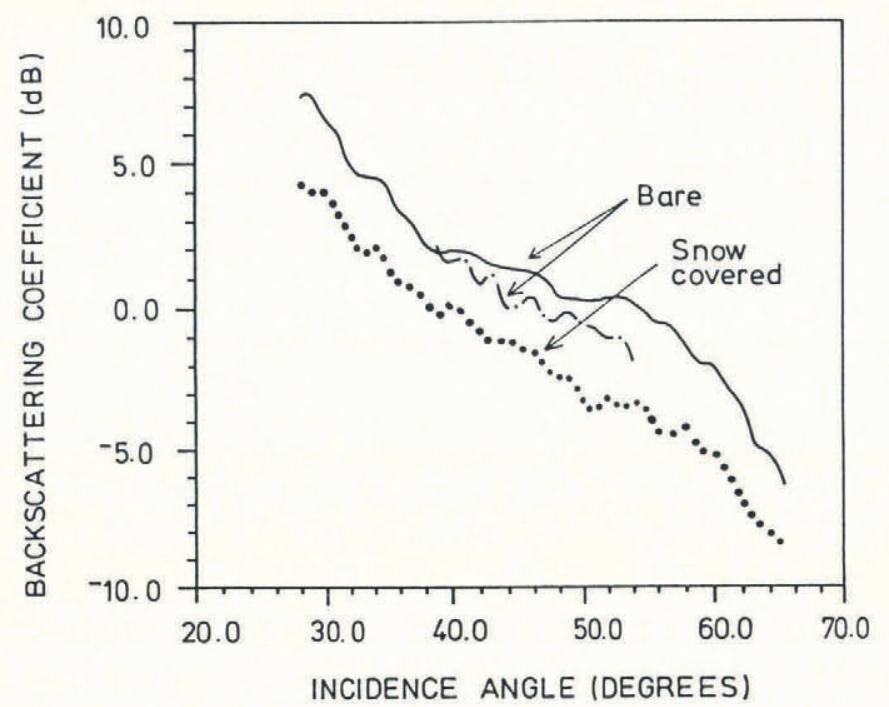

Fig. 6. Back-scattering coefficient for undeformed ice: snowcovered fast ice and bare drift ice (Johansson, 1988).

study data (area II). These were undeformed bare ice, undeformed snow-covered ice and ridged ice. The fast ice was covered by a $0-30 \mathrm{~cm}$ snow layer which was a few per cent wet; the drift ice, on the other hand, was bare with a basically dry surface (Fig. 2). Figure 6 shows the backscattering coefficient for these undeformed ice types. The dash-dotted curve does not cover the full incidence-angle range due to the presence of a lead $\left(28-39^{\circ}\right)$ and ridges $\left(54-60^{\circ}\right.$ and $\left.61-64^{\circ}\right)$ which have been omitted. The fast ice is clearly separated from the drift ice and gives a $2-3 \mathrm{~dB}$ lower back-scattering coefficient. The difference is about the same for all incidence angles. The result can be explained by the different scattering mechanisms which are present in the two cases. The scattering from the bare drift ice is caused by a combination of surface scattering and volume scattering from the upper $10 \mathrm{~cm}$ ice layer. In the case of this fast ice, the scattering came from the snow rather than from the ice, giving a low level (Kim and others, 1984).

In the drift-ice area the mean value of the back-scatter for the bare undeformed ice and ridges was compared by Johansson (1988) using the BEPERS pilot-study data. A heavily ridged zone between incidence angles $51^{\circ}$ and $65^{\circ}$ was found to give a $2-5 \mathrm{~dB}$ higher back-scatter than undeformed ice. Several of the ridge pixels were saturated due to the limited dynamic range of the SAR. This information can be used to characterize the ridge properties and the intensity of ridging.

The chaotic nature of the ice-block piles and the snow content in between the blocks mean that it is impossible to present a detailed model describing the scattering of electromagnetic waves by ice ridges. Instead, a statistical interpretation has to be given where the mean properties of scattering over a given area of an ice ridge are studied and related to the mean properties of the ice ridge. Such an analysis needs a long-term programme with simultaneous ground measurements and SAR measurements before an interpretation key can be derived. So far, the number of simultaneous measurements is too small. As a first step, a simple ice-ridge model was developed (see Fig. 7). This model includes three contributions: the triangular shape of

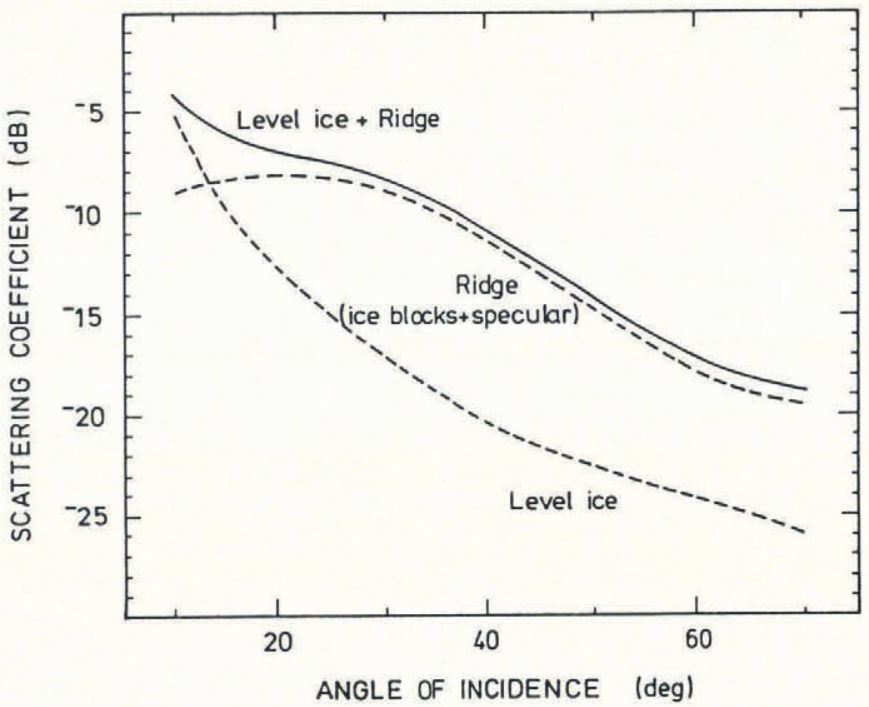

Fig. 7. Principal illustration of the radar back-scattering cross-section (Askne and Johansson, 1988).

ridge sails, which leads to a tilt effect enhancing scattering from the front side, the individual ice blocks with angles of incidence distributed around the sail inclination angle, and the specular component caused by blocks facing the radar or corners causing enhanced scattering. An advanced model including the full three-dimensional geometry of ridge sails has been developed by Manninen (1990). Her results show that the shape and orientation of ice blocks are very important but not the triangular geometry of ridge sails itself. This will make it difficult to distinguish between ridges and brash ice. The detection of ice ridges by SAR is dependent not only on the ridge properties but also on the SAR, and in particular its resolution and dynamics.

A visual comparison between the aerial photography and the VARAN-S SAR images showed that in the order of $50-70 \%$ of the ice ridges in the aerial photographs show up in the SAR images at incidence angles of $57-65^{\circ}$ (Askne and Johansson, 1988). A good resolution as in VARAN-S SAR is important to identify individual ridges and characterize their properties.

Some general properties of radar imaging of ice ridges have been obtained by comparing the SLAR and SAR images (Johansson and others, 1988). In one case the same area was covered by SAR and SLAR from different viewing directions, i.e. a small incidence angle in the $S A R$ image corresponds to a large one in the SLAR (Fig. 8). We find that ice ridges and fractures show up better at higher incidence angles and this effect compensates for the coarse resolution of the SLAR.

\section{GEOPHYSICAL VALIDATION}

\subsection{General}

Geophysical validation of SAR imagery sets limits to its usefulness as a sea-ice observation instrument. Image analysis and back-scatter investigations are powerful background tools. In the BEPERS pilot study, the key validation observations were ice- and snow-thickness 

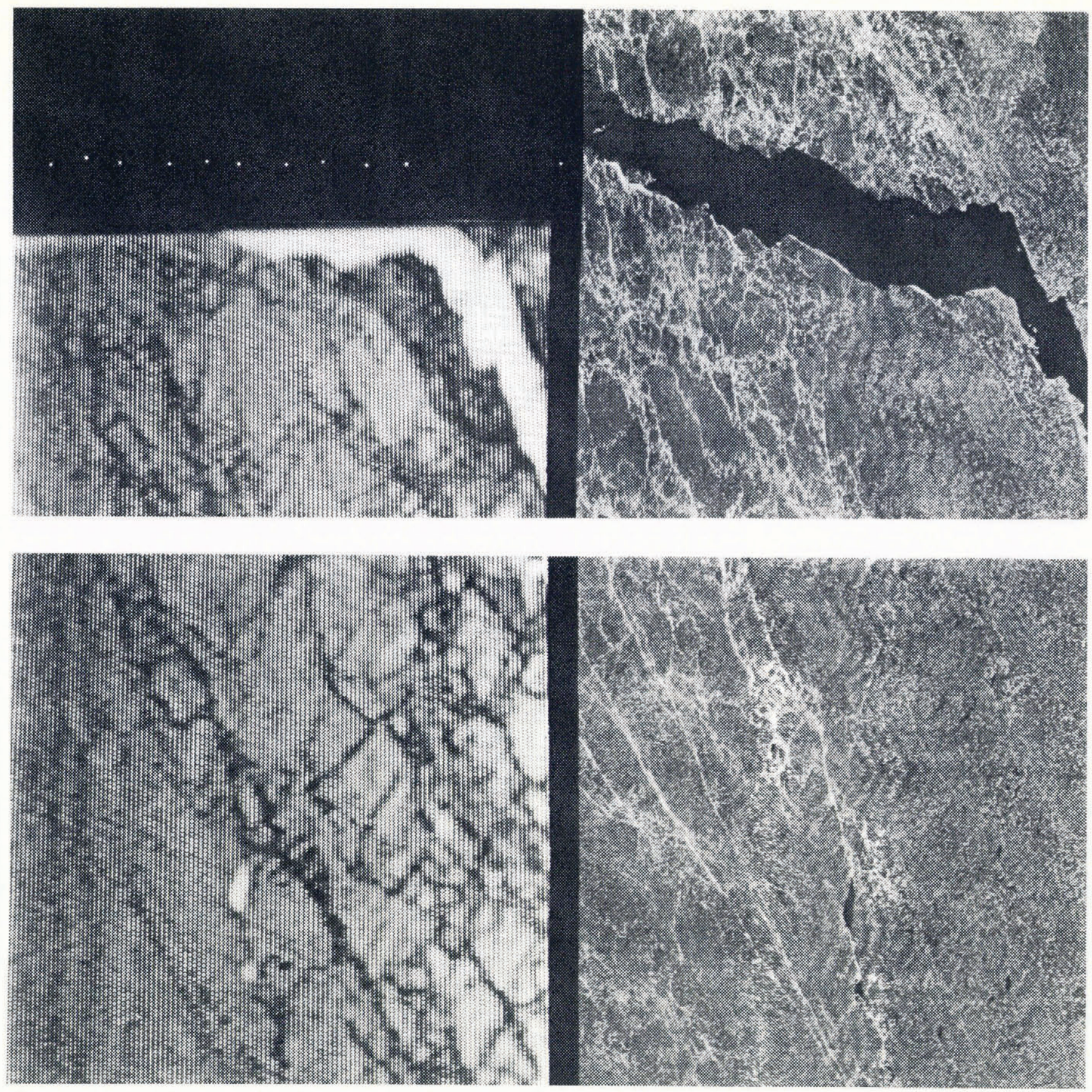

Fig. 8. Overlapping SLAR (negative) and SAR data in area II. The SLAR to the left, imaged to the left; the SAR to the right, imaged to the right.

measurements, ice-morphology observations and aerial photography. These data are used to discriminate between ice and open water, determine ice type, determine ice compactness, and identify ice ridges and ice floes. Very important additional ground data would be the surface roughness over a wide range of spatial frequencies but not much information on this could be collected (Leppäranta and others, 1988). Small-scale roughness features (millimetre to centimetre wavelengths) were studied using visual and photographic methods (see Figs 3 and 4). The structure of ridge sails was also mapped describing the external sail geometry, size and orientation of ice blocks, and the distribution of voids (Kankaanpää, 1988).

Visual inspection of processed and rectified images illustrates well the basic possibilities and problems in the interpretation of SAR imagery (Figs 8 and 9). Spots with variable strength of return appear. Open water is dark (low return) whereas ice is generally brighter. Deformed ice gives the highest return. The first-order ice-water discrimination is based on the back-scatter level but such a method has a limited efficiency. In Figure 8 a lead crossing a ridged pack-ice area is seen in the upper right image. The low-return region is here a lead but such is not always the case. As an example, Figure 9 shows a lead-type black region but ground observations showed that it was $50 \mathrm{~cm}$ thick bare and very smooth ice. Ridges appear as bright lines in the images. This looks fine. However, at the lead edges (Fig. 8) there is some brash ice packed loosely 


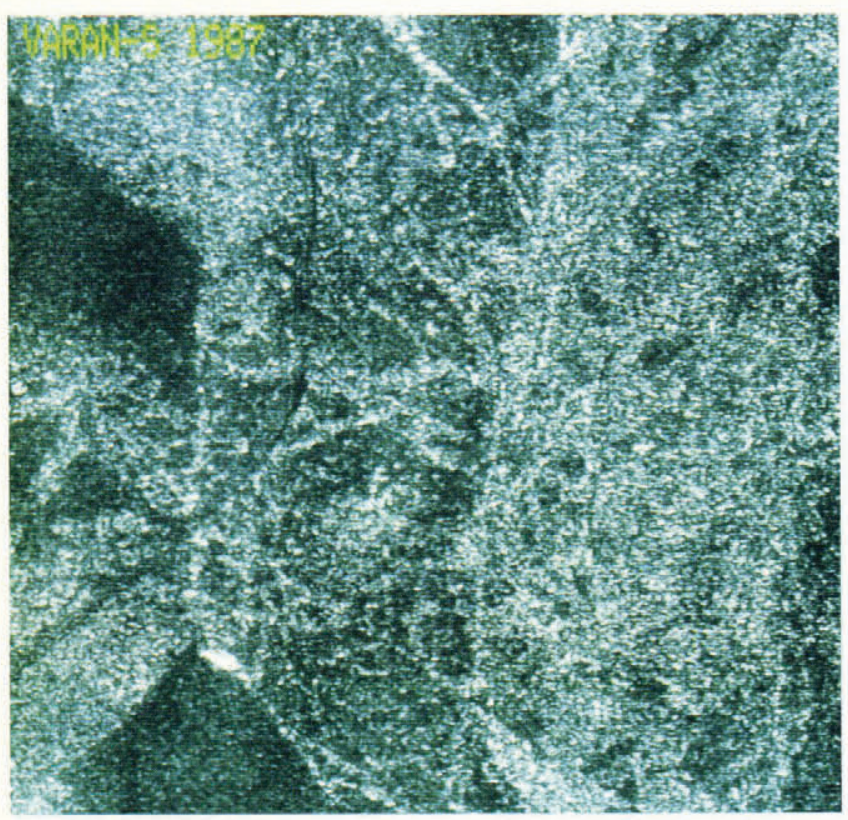

Fig. 9. An example of VARAN-S X-band $S A R$ images from area I. The image size is $5 \mathrm{~km} \times 5 \mathrm{~km}$, and the incidence angle ranges from $16^{\circ}$ (right) to $67^{\circ}$ (left). Black for low return and white for high return.

together by the wind and these brash-ice lines give about the same return as the ridges.

\subsection{Cases}

Several interesting and illustrative cases were found from the data:

(i) Ice-thickness unpredictability. Surface scattering is very important in the Baltic brackish water ice pack, and consequently the surface roughness-thickness relation indicates the usefulness of SAR for ice-thickness estimates. There seems to be some meaningful correlation, since old and thick ice is often rather uneven while newly formed ice is generally smoother. The correlation is, however, not very high; a good example of thickness unpredictability was illustrated by the black spots in Figures 8 and 9 showing similar returns for open water and $50 \mathrm{~cm}$ thick smooth ice.

(ii) Ship channels. The brightest areas in the SAR imagery appeared to be ship channels. This was true for frequently used tracks such as the Vaasa-Umeå route (in the archipelago) as well as for those used only once or twice. The surface area of broken ice pieces is larger in ship channels than in ridges and therefore the return tends to be stronger in ship channels.

(iii) Air-bubble effects. In area II a bare level patch with a lot of air bubbles at the ice surface was found. The surface structure is shown in Figure 4. The size of the air bubbles was from millimetres up to $3-4 \mathrm{~cm}$, i.e. up to the X-band wavelength. This patch gave much stronger back-scatter than level ice, bare or snow-covered, elsewhere. The enhanced back-scatter may be due to the air bubbles which mainly determine the volume scattering. However, the relative importance of the various scattering mechanisms cannot be settled from the existing data.

(iv) Waves in ice field. In area IV there was a moderate onice wind which packed the ice edge and induced a significant wave height of $1-1.5 \mathrm{~m}$ in the open sea (Leppäranta, 1988). From the SAR imagery (Johansson and others, 1988), these waves were seen to penetrate into the ice. This was the first illustration of this phenomenon in the Baltic Sea. The penetration length is basically determined by the incoming wave spectrum and the vertical and horizontal size of the ice floes, and therefore provides ice information.

\subsection{Ice-type classification}

Ice-type classification is a fundamental problem in the interpretation of SAR (or any other kind of remotely sensed) data. In a first-year ice pack such as in the Baltic Sea, the first natural class division is ice and open water. Further sub-division in the ice class should proceed in terms of ice thickness and the degree of deformation.

Ice-type classification has been examined by Kemppainen (1989), using the BEPERS pilot-study lowresolution SAR imagery. On the basis of the validation data she defined eight ice types: (1) lead (open water), (2) bare smooth ice, (3) patchy (ice-snow) level ice, (4) snowcovered ice, (5) frozen uneven ice, (6) old ridges, (7) young ridges, and (8) brash ice. Of these ice types, the first four represent water or undeformed ice surfaces and the other four deformed ice surfaces with broken ice pieces. In order to determine the radar reflectivity distribution for these ice types, several small areas were investigated; these areas were chosen on the basis of the aerial photography. The mean and variance of back-scatter were calculated for each ice type.

Quantitative results were obtained supporting the visual inspection described in section 6.1 . Figure 10 shows the mean image intensity and its standard deviation for the eight ice types. The mean is directly related to the back-scattering coefficient. Basically, it is easy to discriminate open water/undeformed ice and deformed ice from each other but a finer classification becomes difficult. The open-water signatures are quite different in areas I and II due to dependence on the wind conditions but still closely associated within the three undeformed ice types. For deformed ice, young ridges give a notably higher backscatter than old ridges, which may be due to snow conditions, surface-roughness erosion or freshening of the sail blocks. The very high back-scatter from brash ice appears clearly.

Two basic problems of high practical importance arise: how to discriminate between (1) open water and undeformed ice, and (2) brash ice and ridged ice. The back-scatter histograms were similar for both surface types in both problems (Kemppainen, 1989). Therefore, distribution statistics other than the average do not help, e.g. the standard deviation of the image intensity within the ice classes gave results similar to those using the mean. Ambiguities of these statistics between different ice types lead to a need for utilizing more sophisticated methods for examining the separability of classes. The static geometry 


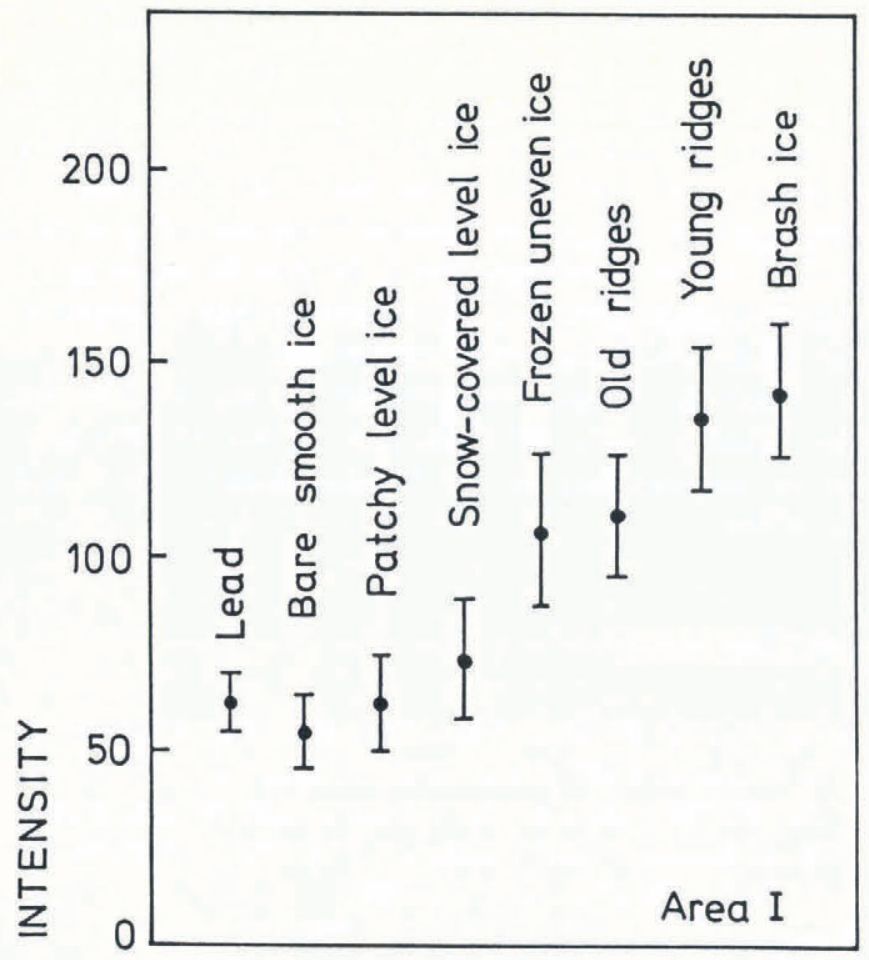

a

LEVEL SURFACE BROKEN ICE

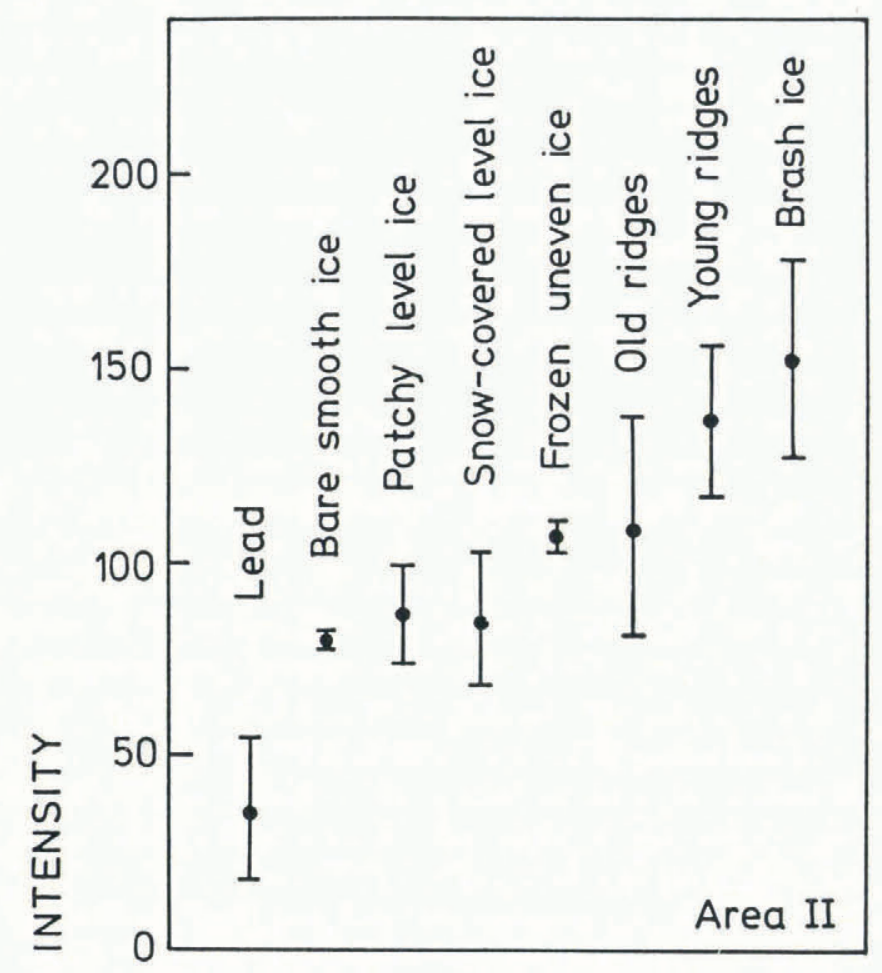

\section{b LEVEL SURFACE BROKEN ICE}

Fig. 10. Ice-type classification result from $V A R A N-S X$ band SAR data (Kemppainen, 1989). (a) Area I; (b) Area II.

probably is a bad guide for the open water-undeformed ice and ridged ice-brash ice separations. But the dynamics of the geometry might help due to the large difference in resistance to deformation within these pairs.
On the basis of the classification results, box segmentation was applied to the imagery (Kemppainen, 1989). Classification limits were determined for four classes: (1) open water or bare smooth ice, (2) smooth or slightly deformed ice, (3) ridges, and (4) brash ice. As an example, Figure 11 shows the classification-segmentation results for the SAR image given in Figure 9. In spite of the speckled appearance of the original image, areas of smooth or slightly deformed ice show up fairly well as one class. Linear features are preserved, as image averaging in a small $(3 \times 3)$ window is used. The classified image is not essentially better for visual inspection than the original pre-processed image but it is highly compressed and can easily be transmitted to ships.

\section{CONCLUSIONS}

A successful SAR experiment, the BEPERS pilot study, has been carried through in the northern part of the Baltic Sea. A summary list of the data obtained is shown in Table 1. The data have been used for developing methods for SAR image analysis, back-scatter modelling investigations and geophysical validation of SAR imagery over the Baltic Sea brackish water ice. SAR is capable of providing highresolution ice information independent of weather. The question is: how do we interpret this information? Many of the present results are qualitative but are based on a thorough investigation of the data and provide a proper understanding of the potential of SAR in the Baltic Sea. Quantitative results were obtained for the back-scatter characteristics of various ice types. This is very much the state of the art in SAR sea-ice mapping in general (e.g. Carsey, 1989). Advanced algorithms may become available only when large amounts of sequential SAR imagery have been produced by satellites.

The SAR imagery was cleaned up by speckle

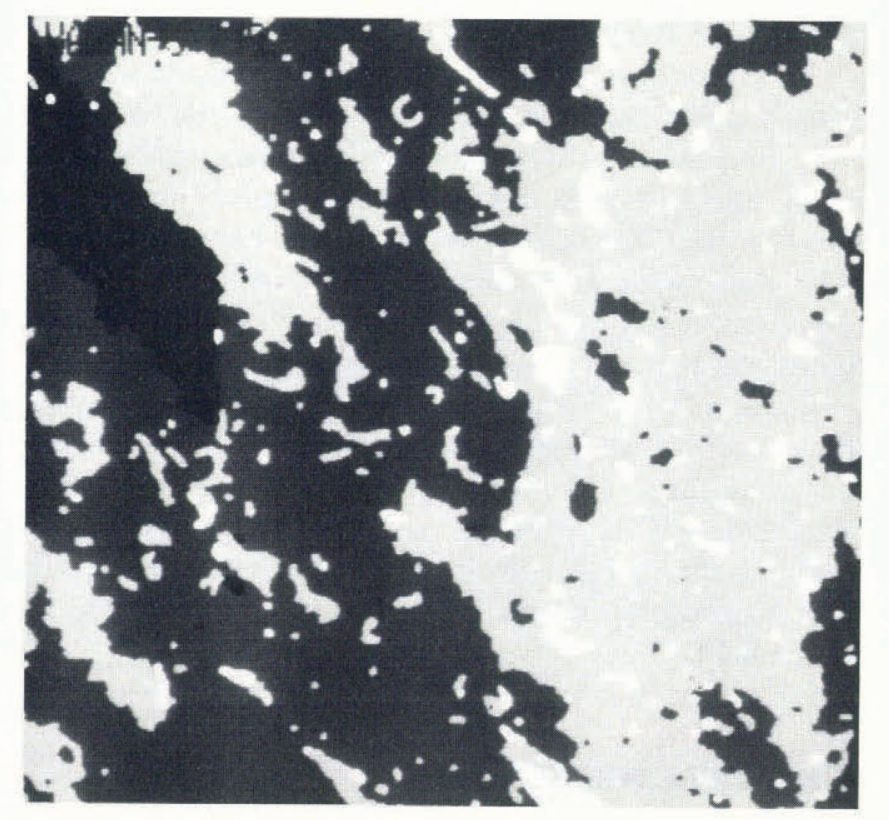

Fig. 11. An example of segmented image based on the original given in Figure 9 (Kemppainen, 1989). 
reduction. Segmentation methods were investigated using the box-classification scheme. Back-scatter characteristics for undeformed ice and ridges were quantitatively examined. Ridges gave a $2-5 \mathrm{~dB}$ higher return which gives promise for the usefulness of back-scatter models. The detection of ridges was, however, shown to be very much dependent on the angle of incidence.

For the geophysical validation of SAR imagery, the data set provided very good examples of the problems and difficulties in the interpretation of SAR data. Eight ice types were defined and the statistics of the SAR image intensity were examined for them. Figure 10 presents the ice-type classification results. Clearly, it is easy to discriminate open water/undeformed ice and deformed ice from each other, but a finer classification becomes difficult. Two basic problems of high practical importance arise: how to discriminate between (1) open water and undeformed ice, and (2) brash ice and ridged ice. It is expected that much improved results will be obtained through multiple radar parameters, through more advanced statistical and structural analysis of the digital data, and through having series of consecutive images available.

In all, the BEPERS pilot study provided an excellent data set and formed the basis of understanding of how to work with SAR imagery over the Baltic Sea ice. This experiment also gave most useful practical as well as scientific information for undertaking the BEPERS main experiment in the following winter (Thompson and Leppäranta, 1988).

It is now strongly believed that future operational SAR systems (ERS-1, ERS-2, JERS, Kosmos, Radarset, Polar Platform) will open a new era for the ice services in the Baltic Sea. The first real test will be the PIPOR Baltic Sea application/demonstration experiment to be undertaken in 1992. Then ERS-1 SAR images will be transmitted to ice services, winter-navigation authorities and icebreakers in near real time. ERS-1 SAR will work at C-band, VV-polarization and an incidence angle of $23^{\circ}$. However, in spite of the differences from the VARAN-S $\mathrm{SAR}$, the present results have given very valuable guidance for learning how to use ERS-1 data.

In future operational systems, SAR products will not be used alone but in combination with weather-satellite data, occasional ground and aerial observations, and maybe also with products from mathemetical models (cf. Leppäranta, 1986). The question is then how to combine SAR data with the other types of information. In numerical modelling of sea-ice dynamics and thermodynamics, real data are needed for initialization and verification. In initialization, SAR provides all-weather information of ice compactness, thickness (via ice type) and roughness. For the verification of ice-dynamics calculations, SAR provides an all-weather system for mapping the spatial velocity field, which is particularly interesting during storms when drastic changes occur in the ice field.

\section{ACKNOWLEDGEMENTS}

Six Finnish and seven Swedish Institutes contributed to the field programme; Finland: Army Map Service, Finnish
Institute of Marine Research, Helsinki University of Technology, National Board of Survey, Technical Research Centre of Finland and University of Helsinki; Sweden: Chalmers University of Technology, Lund University of Technology, Swedish Administration of Shipping and Navigation, Swedish Coast Guard, Swedish Defense Research Establishment, Swedish Meteorological and Hydrological Institute and Swedish Space Corporation. Their efforts are greatly appreciated.

Financial support was provided by the Technology Development Centre (TEKES) and the Board of Navigation in Finland and by the Swedish Agency for Space Activities.

\section{REFERENCES}

Askne, J. and R. Johansson. 1988. Ice ridge observations by means of SAR. In Guyenne, T. D. and J.J. Hunt, eds. IGARSS'88; remote sensing: moving towards the 21st century, 12-16 September 1988, Edinburgh, U.K. Vol. 2. Noordwijk, ESTEC, 801-803. (ESA SP-284.)

Battrick, B. and E. Rolfe, eds. 1985. A Programme for International Polar Oceans Research (PIPOR). Paris, European Space Agency. (ESA SP-1074.)

Carsey, F. 1989. Review and status of remote sensing of sea ice. IEEE 7. Oceanic Eng., 14(2), 127-138.

Finnish Institute of Marine Research. 1987. Baltic Sea ice chart No. 46, 2 April 1987. Helsinki, Finnish Institute of Marine Research.

Håkansson, B. and T. Thompson. 1988. Ground truth measurements for SAR-data interpretation at study area III. Winter Navigation Research Board. Research Report (Helsinki) 45, 85-101.

Hallikainen, M. 1984. Microwave remote sensing of snow. Espoo, Helsinki University of Technology. Radio Laboratory.

Hallikainen, M., M. Toikka and J. Hyyppä. 1988. Microwave measurements of ice and snow. Winter Navigation Research Board. Research Report (Helsinki) 45, 69-83.

Johansson, R. 1988. Evaluation of VARAN-S SAR data from the BEPERS pilot study. In Guyenne, T.D. and J.J. Hunt, eds. IGARSS'88; remote sensing: moving towards the 21st century, 12-16 September 1988, Edinburgh, U.K. Vol. 2. Noordwijk, ESTEC, 817-818. (ESA SP-284.)

Johansson, R. and J. Askne. 1987. Modelling of radar backscattering from low-salinity ice with ice ridges. Int. f. Remote Sensing, 8(11), 1667-1677.

Johansson, R., L. Ulander and J. Askne. 1988. Airborne radar observations. Winter Navigation Research Board. Research Report (Helsinki) 45, 119-147.

Kankaanpää, P. 1988. Structure of a pressure ridge in the Baltic Sea. Geophysica, 24, 15-33.

Kemppainen, H. 1989. Synteettisen apertuurin tutkan soveltuvuus jään tulkintaan Pohjanlahdella [Applicability of synthetic aperture radar in interpretation of sea ice in the Baltic Sea]. (M.Sc. thesis, Helsinki University of Technology. Department of Civil Engineering and Surveying.)

Kim, Y., R. G. Onstott and R. K. Moore. 1984. The effect of a snow cover on microwave backscatter from sea ice. IEEE f. Oceanic Eng., 9, 383-388. 
Kuittinen, R. 1988. SAR flight. Winter Navigation Research Board. Research Report (Helsinki) 45, 17-29.

Lee, J.S. 1986. Speckle suppression and analysis for synthetic aperture radar images. Opt. Eng., 25, 636-643.

Leppäranta, M. 1986. Ice information systems for marine operations. In POLARTECH'86; International Offshore and Navigation Conference and Exhibition, Helsinki, Finland, 27-30 October 1986. Vol. 1. Espoo, Technical Research Centre of Finland, 57-70.

Leppäranta, M. 1988. Ground data for area IV. Winter Navigation Research Board. Research Report (Helsinki) 45, 103-106.

Leppäranta, M. and T. Thompson. 1989. BEPERS-88; sea ice remote sensing with synthetic aperture radar in the Baltic Sea. Eos, 70(28), 698-699, 708-709.

Leppäranta, M., T. Manninen, P. Kosloff and E. Palosuo. 1988. Ice and snow geophysics in area II. Winter Navigation Research Board. Research Report (Helsinki) 45, 41-68.

Leppäranta, M., R. Kuittinen and H. Kemppainen. 1989. Preparations to use Synthetic Aperture Radar (SAR) in sea ice remote sensing in the Baltic Sea. Adv. Space Res., 9, 209-212.

Manninen, T. 1990. A model for microwave surface backscattering from an ice ridge. In Proceedings of the 9th
EARSeL Symposium in Espoo, Finland, 27 June -1 July 1989. Luxembourg, Office for Official Publications of the European Communities, 176-181.

Thompson, T. and M. Leppäranta, eds. 1988. BEPERS-88 Experiment plan. Final edition. Winter Navigation Research Board. Research Report (Norrköping), 46.

Vaillant, D. 1985. VARAN-S; an airborne synthetic aperture radar for research in microwave remote sensing. In Proceedings of the EARSeL/ESA Symposium on European Remote Sensing Opportunities. Paris, European Space Agency, 165-174. (ESA SF-233.)

Vaillant, D. and A. Wadsworth. 1987. Preliminary results of some remote sensing campaigns of the French airborne SAR VARAN-S. In IGARSS'87. Remote Sensing: Understanding the Earth as a System, 18-21 May 1987, University of Michigan, Ann Arbor, Michigan, 495-500.

Vainio, J. 1988. Ground base I. Winter Navigation Research Board. Research Report (Helsinki) 45, 31-40.

Winter Navigation Research Board. 1988. BEPERS (Bothnian Experiment in Preparation for ERS-1) pilot study. Data report. Winter Navigation Research Board. Research Report (Helsinki) 45.

The accuracy of references in the text and in this list is the responsibility of the authors, to whom queries should be addressed. 